\title{
ACUPUNCTURE EFFECTIVENESS AS A COMPLEMENTARY THERAPY IN FUNCTIONAL DYSPEPSIA PATIENTS
}

\author{
Flávia Altaf da Rocha LIMA, Lincoln Eduardo Villela Vieira de Castro FERREIRA and \\ Fábio Heleno de Lima PACE
}

\begin{abstract}
Context - Functional dyspepsia represents a frequent gastrointestinal disorder in clinical practice. According to the Roma III criteria, functional dyspepsia can be classified into two types as the predominant sympton: epigastric pain and postprandial discomfort. Even though the pathophysiology is still uncertain, the functional dyspepsia seems to be related to multiple mechanisms, among them visceral hypersensitivity, changes in the gastroduodenal motility and gastric accommodation and psychological factors. Objective - Evaluate the effectiveness of acupuncture as a complementary to conventional treatment in functional dyspepsia patients. Methods - Randomized clinical trial in which were enrolled patients with functional dyspepsia patients in according with Rome III criteria. One group was submitted to drug therapy and specific acupuncture (GI) and the other to drug therapy and non-specific acupuncture (GII). The gastrointestinal symptoms, presence of psychiatric disorders and quality of life were evaluated, at the end and three months after treatment. Results - After 4 weeks of treatment there was improvement of gastrointestinal symptoms in Group I ( $55 \pm 12$ vs $29 \pm 8.8 ; P=0.001)$ and Group II ( $50.5 \pm 10.2$ vs $46 \pm 10.5 ; P=0.001)$. Quality of life was significantly better in Group I than group II (93.4 \pm 7.3 vs $102.4 \pm 5.1 ; P=0.001)$. Anxiety $(93.3 \%$ vs $0 \% ; P=0.001)$ and depression $(46.7 \%$ vs $0 \%$; $P=0.004)$ were significantly lower in Group I than group II. When comparing the two groups after 4 weeks of treatment, gastrointestinal symptoms ( $29 \pm 8.8$ vs $46 \pm 10.5 ; P<0.001)$ and quality of life $(102.4 \pm 5.1$ vs $96 \pm 6.1 ; P=0.021)$ were significantly better in Group I than group II. Three months after the treatment, gastrointestinal symptoms remained better only in Group I, when compared to the pre-treatment values ( $38 \pm 11.3$ vs $55 \pm 12 ; P=0.001)$. Conclusion - In patients with functional dyspepsia the complementary acupuncture treatment is superior to conventional treatment. Further studies with more patients are needed to confirm these findings. KEYWORDs - Acupuncture therapy. Complementary therapy. Dyspepsia.
\end{abstract}

\section{INTRODUCTION}

Functional dyspepsia (FD) represents a frequent gastrointestinal disorder in clinical practice. It is estimated that $15 \%$ to $40 \%$ of the western population have this disorder ${ }^{(6)}$. According to the Rome III criteria, FD can be defined by the presence of pain or discomfort in upper region of the abdomen associated or not to postprandial discomfort and early satiety without significant alterations at the digestive endoscopy. According to the same criteria, FD can be classified into two types as the predominant sympton: epigastric pain (EP) and postprandial discomfort (PPD) ${ }^{(2)}$. Even though the pathophysiology is still uncertain, the FD seems to be related to multiple mechanisms, among them visceral hypersensitivity, changes in the gastrodu- odenal motility and gastric accommodation and psychological factors ${ }^{(23)}$.

Treatment of FD most often requires the use of medications for controlling the symptoms. However, for being a recurrent disorder and by presenting various etiopathogenic mechanisms, often the conventional therapy is not effective ${ }^{(20)}$. This situation makes the treatment of FD a great challenge, it is necessary to search for more integrative methods, capable of covering the multiplicity of its triggering agents. Acupuncture, one of the resources of Traditional Chinese Medicine (TCM), has been widely used as complementary therapy for various disorders including the gastrointestinal diseases. Even though there has not yet been a consensus formed on the exact integration of neurophysiological and neuroendocrine effects of acupuncture, there are several studies that 
indicate its specific effects on pain, anxiety, depression and gastrointestinal disorders. One of the effects of acupuncture in pain would be stimulation of the A-delta fiber afferents, which mobilize the endorphin cascade, monoamine excitement, and in the descending serotonin inhibitory track ${ }^{(28)}$. Its effect would also be associated with the increased serotonin and norepinephrine production; it would relieve endogenous opioids and would regulate the autonomic nervous system ${ }^{(3)}$. In the gastrointestinal tract, acupuncture works in a comprehensive manner. Studies have found that transcutaneous electrical stimulation of acupoints PC6-ST36 promoted the acceleration of gastric emptying in patients with FD and in healthy volunteers reduced the gastric dysrhythmia ${ }^{(26)}$. In patients with chronic atrophic gastritis acupuncture caused a reduction of gastrin secretion, possibly mediated by integrating the humoral and neural pathways ${ }^{(17)}$.

The interest in studies using acupuncture in randomized clinical trials (RCT) has significantly increased in recent years. As a result, a series of recommendations was created (Standards for Reporting Interventions in Controlled Trials of Acupuncture - STRICTA) with the aim of structuring and clarifying acupuncture research, establishing it safely and reproducibly in the light of evidence-based medicine, as a highly useful and effective complementary method ${ }^{(11)}$. Therefore, the aim this study is to evaluate the effectiveness of acupuncture as a complement to conventional treatment in patients with functional dyspepsia.

\section{METHODS}

Single-blind randomized clinical trial study Approved by the Research Ethics Committee of the Federal University of Juiz de Fora (protocol: 0045/2010). Patients assisted in the Gastroenterology outpatient clinic of the University Hospital, during the period from June 2010 to June 2011, with 18 to 60 years with FD in accordance with Rome III criteria were included. All patients were evaluated clinically and were submitted to upper gastrointestinal endoscopy with testing for Helicobacter pylori ${ }^{(21)}$. The study excluded individuals who presented Helicobacter pylori infection, current or recent use (four weeks) of non-steroid anti-inflammatory (NSAIDS), acetylsalicylic acid, prokinetics, acid secretion inhibitors, as well as pregnant women, acuphobics and chronic diseases (chronic obstructive pulmonary disease, severe heart disease, liver cirrhosis, chronic pancreatitis, and chronic renal disease). The patients by simple random sampling, were divided into two groups: Group I (GI drug therapy associated with a specific acupuncture) and Group II (GII - drug therapy associated with non-specific acupuncture).

For the evaluation of gastrointestinal symptoms, was used the Gastrointestinal Scale Related Symptoms (GSRS). This is a standardized questionnaire that consists of 15 questions, graduating from 0 to 7 , which deal with various symptoms related to the gastrointestinal tract, including epigastric pain and post-prandial discomfort. Any reduction in the GSRS scale score obtained was considered symptoms improvement ${ }^{(22)}$. To analyze the influence of anxiety disorders or depression on the efficacy of treatment and its behavior in the different groups the Hospital Anxiety and Depression Scale (HADS) was used, which consists of 14 questions, seven are focused on analysis of anxiety (HADS-A) and seven for depression (HADS-D). Each question can be scored from zero to three, totaling 21 points for each domain (anxiety and depression). For the characterization of these disorders the recommended cutoff points by Zimond and Snaith were adopted: HADS-A $\geq 9$ $=$ anxiety; HADS-D $\geq 9=$ depression $^{(13)}$.

To assess quality of life indices Short-form Health Survey Quality of Life (SF-36) questionnaire was applied. This is a generic instrument to comprehensively measure the health-related quality of life, addressing aspects relating to eight different domains: functional ability, physical appearance, social aspects, pain, mental health, emotional health, vitality and general health status. Each domain can receive a score of 0 to 100 , where 0 indicates the worst health status and 100 the best ${ }^{(4)}$. Each of the scales was applied at three distinct times: immediatelly before (time 1), on the day following the end of treatment (time 2) and 3 months after the treatment (time 3 ). The form responses were completed by the patient (self-reporting).

The medication treatment lasted four weeks and was established according to the FD type. For patients with functional dyspepsia PPD type domperidone $10 \mathrm{mg}$ was prescribed, 30 minutes before main meals (breakfast, lunch and dinner) and for those with functional dyspepsia EP type, omeprazole $20 \mathrm{mg}, 30$ minutes before breakfast. Both groups were instructed as to the dietary and behavioral modifications.

The acupuncture treatment was conducted during 4 weeks, concomitant drug therapy, in twelve sessions, three times per week, with approximate 40 minutes duration, in a specific room at University Hospital. All procedures were performed by an experienced researcher in the acupuncture therapy. Having as reference points used by classical literature (according to the principles of TCM) and current for FD treatment, two treatment plans involving 10 acupoints were prepared $^{(5,25)}$. In GI, the points were active in the reduction of referred symptoms (PC6, LI4, CV12, ST36, L3, ST44), while in GII, the 10 acupoints were on the same meridian, but with one less measure at the location (points without primary FD indications: PC5, LI3, CV11, ST35, L2, ST43). This criterion was used to ensure uniformity and similarity in clinical procedure ${ }^{(24)}$.

The point location methods met the anatomical relationship criteria (characteristic anatomical location) and the proportional distance measuring of the points (using the Tsun unit of measure, defined by the length of the fingers of each individual patient $)^{(5)}$. Disposable acupuncture needles, stainless steel measuring $70 \mathrm{~mm} \times 0.40 \mathrm{~mm}$ were used, after local cleansing alcohol $70 \%$. The needles were introduced to the specific anatomical regions of each point, obeying the depth and response principles elicited from each group. 


\section{RESULTS}

Thirty patients with FD were included. The groups were similar in relation to gender, marital status and educational level. The mean age of patients in the GI was significantly lower than GII ( $34.1 \pm 11.3$ vs $46.5 \pm 9.7 ; P=0.003)$, as shown in table 1 . As to the type of FD, 11 patients $(36.7 \%)$ were classified as dyspepsia type DPP and $19(63.3 \%)$ as the $\mathrm{EP}(P=0.705)$. Anxiety disorder was more common among the patients of GI ( $93.3 \%$ vs $46.7 \%, P=0.005)$, whereas the presence of depressive disorder showed no difference $(46.7 \%$ vs $26.7 \% ; P=0.256)$. The mean of the gastrointestinal symptom indices ( $55 \pm 12$ vs $50.5 \pm 10.2 ; P=0.276)$ and quality of life (93.4 \pm 7.3 vs $95 \pm 6.7 ; P=0.412)$ was similar in both groups (Table 1).

TABLE 1. General characteristics of the sample according to the groups I and II $(\mathrm{n}=30)$

\begin{tabular}{|c|c|c|c|}
\hline Variables & $\begin{array}{c}\text { GI } \\
(\mathrm{n}=15)\end{array}$ & $\begin{array}{c}\text { GII } \\
(\mathrm{n}=15)\end{array}$ & $\begin{array}{c}P \\
\text { value }\end{array}$ \\
\hline $\begin{array}{l}\text { Gender } \\
\quad \text { Female - n (\%) }\end{array}$ & $13(86.7 \%)$ & $11(73.3 \%)$ & 0.610 \\
\hline Age (average \pm SD) & $34.1 \pm 11.3$ & $46.5 \pm 9.7$ & 0.003 \\
\hline $\begin{array}{l}\text { Marital status } \\
\text { Married n (\%) }\end{array}$ & $6(40.0 \%)$ & $10(66.7 \%)$ & 0.273 \\
\hline $\begin{array}{l}\text { Education } \\
\quad \text { Average level } \mathrm{n}(\%)\end{array}$ & $6(40.0 \%)$ & $6(40.0 \%)$ & 0.135 \\
\hline $\begin{array}{c}\text { DyspepsiaType } \\
\text { EP - n (\%) } \\
\text { PPD - n (\%) }\end{array}$ & $\begin{array}{l}10(66.7 \%) \\
5(33.3 \%)\end{array}$ & $\begin{array}{l}9(60.0 \%) \\
6(40.0 \%)\end{array}$ & 0.705 \\
\hline GSRS (average \pm SD) & $55 \pm 12$ & $50.5 \pm 10.2$ & 0.276 \\
\hline Quality of life (average \pm SD) & $93.4 \pm 7.3$ & $95 \pm 6.7$ & 0.412 \\
\hline Anxiety - n (\%) & $14(93.3 \%)$ & $7(46.7 \%)$ & 0.005 \\
\hline Depression - n (\%) & $7(46.7 \%)$ & $4(26.7 \%)$ & 0.256 \\
\hline
\end{tabular}

$P<0.05$; EP: epigastric pain; PPD: postprandial discomfort; GSRS: index of gastrointestinal symptoms

\section{Efficacy Analysis - end of the treatment (time 2)}

At this time, it was possible to demonstrate that there was improvement of gastrointestinal symptoms in GI ( $55 \pm$ 12 vs $29 \pm 8.8 ; P=0.001)$ and GII $(50.5 \pm 10.2$ vs $46 \pm 10.5$; $P=0.001)$. In group I the quality of life showed a significant increase compared to the baseline ( $93.4 \pm 7.3$ vs $102.4 \pm 5.1$; $P=0.001)$ while in GII no significant difference was observed (95 \pm 6.7 vs $96.4 \pm 6.1 ; P=0.122)$. The frequency of anxiety disorder $(93.3 \%$ vs $0 \% ; P=0.001)$ and depression $(46.7 \%$ vs $0 \% ; P=0.004$ ) was significantly lower in patients undergoing in the group I. In the GII the anxiety and depressive disorder ( $46.7 \%$ vs $41.7 \% ; P=0.019)(26.7 \%$ vs $20 \% ; P=0.019)$ were similar in the two moments, respectively

The magnitude of gastrointestinal symptoms improvement $(29 \pm 8.8$ vs $46 \pm 10.5 ; P<0.001)$ and quality of life indices $(102.4 \pm 5.1$ vs $96.4 \pm 6.1 ; P=0.021)$ were greater in group I than group II. There was a trend toward a lower frequency of depressive disorders in GI when compared to GII ( $0 \%$ vs $20 \% ; P=0.068)$. Regarding to anxiety disorder it was possible to demonstrate a significant reduction in GI when compared to GII ( $0 \%$ vs $46.7 \% ; P=0.003$ ) (Table 2 ).

TABLE 2. Measures of effectiveness at the end of treatment (time 2) according to the groups I and II $(\mathrm{n}=30)$

\begin{tabular}{lccc}
\hline Variables & $\begin{array}{c}\text { G I } \\
(\mathbf{n}=15)\end{array}$ & $\begin{array}{c}\text { G II } \\
(\mathbf{n}=15)\end{array}$ & $\begin{array}{c}\boldsymbol{P} \\
\text { value }\end{array}$ \\
\hline GSRS (average \pm SD) & $29 \pm 8.8$ & $46 \pm 10.5$ & $<0.001$ \\
Quality of life (average \pm SD) & $102.47 \pm 5.1$ & $96.4 \pm 6.1$ & 0.021 \\
Anxiety $-\mathrm{n}(\%)$ & $0(0 \%)$ & $7(46.7 \%)$ & 0.003 \\
Depression $-\mathrm{n}(\%)$ & $0(0 \%)$ & $3(20.0 \%)$ & 0.068 \\
\hline$P<0.05 ;$ GSRS = index of gastrointestinal symptoms & &
\end{tabular}

\section{Efficacy Analysis - 3 months after end of treatment (time 3)}

Gastrointestinal symptoms did not sustain the values observed immediately after the treatment both in GI ( $29 \pm$ 8.8 vs $38 \pm 11.3 ; P=0.002)$ and the GII $(46 \pm 10.5$ vs $54.5 \pm$ $16.4 ; P=0.001)$, however, even with the symptoms relapse, the results of GI were significantly better when compared with those obtained before the treatment ( $38 \pm 11.3$ vs $55 \pm$ $12 ; P=0.001)$, which was not observed in GII $(54.5 \pm 16.4$ vs $50.5 \pm 10.2 ; P=0.067$ ).

Regarding to time 2 the quality of life indices reduction was observed in GI (102.4 \pm 5.1 vs $96 \pm 2.7, P=0.001)$ and the GII (96.4 \pm 6.1 vs $94 \pm 5.8 ; P=0.035)$. By comparing the values at time 3 and at time 1 there was a trend for maintenance of these indices in GI $(96 \pm 2.7$ vs $95 \pm 6.7$; $P=0.059)$ which was not observed in the group undergoing acupuncture in the non-specific points $(94 \pm 5.8$ vs $95 \pm 6.7$; $P=0.341)$ (Table 3).

TABLE 3. Measures of effectiveness 3 months after the end of treatment (time 3) according to the groups I and II $(\mathrm{n}=30)$

\begin{tabular}{lccc}
\hline Variables & $\begin{array}{c}\text { G I } \\
(\mathbf{n}=15)\end{array}$ & $\begin{array}{c}\text { G II } \\
(\mathbf{n}=15)\end{array}$ & $\boldsymbol{P}$ value \\
\hline GSRS (average \pm SD) & $38 \pm 11.3$ & $54.5 \pm 16.4$ & 0.003 \\
Quality of life (average \pm SD) & $96 \pm 2.7$ & $94 \pm 5.8$ & 0.486 \\
Anxiety $-\mathrm{n}(\%)$ & $5(33.3 \%)$ & $8(53.3 \%)$ & 0.269 \\
Depression $-\mathrm{n}(\%)$ & $0(0 \%)$ & $4(26.7 \%)$ & 0.032 \\
\hline
\end{tabular}

$P<0.05 ;$ GSRS $=$ index of gastrointestinal symptoms

The number of patients with anxiety disorder 3 months after treatment was greater when compared to end of treatment in GI $(0 \%$ vs $33.3 \% ; P=0.011)$ and GII $(46.7 \%$ vs $53.3 \%, P=0.007)$. No difference was observed regarding the frequency of depressive disorder in both groups. With regard to the frequency of psychiatric disorders in time 1 vs 3 . It was observed that the proportion of patients with anxiety $(93.3 \%$ vs $33.3 \% ; P=0.002)$ and depressive disorder (46.7\% vs $0 \% ; P=0.016)$ was lower only in the group who 
received acupuncture in specific points (GI). Three months after treatment the proportion of patients with anxiety disorder was lower in GI when compared to GII (33.3\% vs $53.3 \% ; P=0.269$ ) which was not observed in relation to depressive disorder $(0 \%$ vs $26.7 \% ; P=0.032)$. After 12 weeks of treatment, it was observed that gastrointestinal symptoms scores was better in the GI than GII $(38 \pm 11.3$ vs $54.5 \pm$ 16.4; $P<0.003$ ) (Table 3).

\section{DISCUSSION}

FD is a prevalent gastrointestinal disorder in the general population. It presents complex pathogenesis not yet fully established. The currently available drug therapy is often ineffective. In search of better results new therapeutic modalities, such as acupuncture, has been used as an isolated method or complementary to conventional treatment ${ }^{(27)}$. This study prospectively examined the association of acupuncture treatment with standard drug therapy in patients with FD.

The criteria for the choice of clinical acupuncture points were based on the principles of TCM in the several studies that have used acupuncture for the treatment of gastrointestinal disorders, indeed suggestive of efficacy for FD. According to TCM, the classic points active in digestive disorders were selected, among them ST36, ST44 and CV12 (located in the Stomach meridian - ST and the Conception Vessel meridian - CV, respectively). In a recent study, it has been postulated that the stimulation of point ST36 could involve several ascending pathways of pain involved with limbic substrate ${ }^{(1)}$. In concordance with current literature, the acupoints L3, PC6 and LI4 were selected which showed significant results in the dyspeptic symptoms reduction and gastric emptying acceleration ${ }^{(7)}$.

There were 30 patients included with FD, in accordance with Rome III, and it was possible to demonstrate the gastrointestinal symptoms reduction according to the GSRS scale in both groups at the end of treatment, but significantly better in GI. In addition, only in GI could be demonstrated sustained improvement of these symptoms when compared to the pre-treatment values. For the measurement of gastrointestinal symptoms, the GSRS scale was used, which among symptoms evaluated there is the epigastric pain and discomfort post-prandial, cardinal manifestations of FD. Although this questionnaire is not specific for FD, its use in clinical trials related to this disorder are justified as being a standardized instrument, validated, reliable, reproducible and easy interpretation by the patients.

FD pathogenesis is complex and multifactorial. Which pathophysiological mechanism predominates in a given individual is unknown and it is possible that more than one factor is present. The medications usually used for FD treatment certainly does not work in all the mechanisms and the search for complementary therapies is necessary. Studies show that acupuncture works in neural modulation of gastric motility promoting the gastric emptying acceleration, acid secretion reduction and presents an anti-nociceptive effect in visceral hypersensitivity, especially with the stimulation of the
ST36 point ${ }^{(9,14,26)}$. Therefore, the significant improvement of symptoms in the group that received acupuncture in specific points (GI) was possibly caused by the action of acupuncture in distinct physiopathogenic mechanisms.

The effect triggered by acupuncture can vary widely, according to the area in which the needle is inserted. The choice of non-specific points followed the current debates about what, in fact, would be a control group in acupuncture, one of the major challenges encountered in the conduct of clinical trials. Based on probable effects not inert of sham points usually used and in the absence of a standardization for this method in the literature, a choice of points located in the same meridians for comparison was opted for, but with one tsun less (in reference to acupuncture points of the specific group treatment). Although these points are located on the same meridians and to evoke similar responses, in this group (GII) the insertion of needles was superficial, without obtaining the DeQi. This way, the acupuncture effects were not obtained ${ }^{(8)}$.

In studies using neuroimaging, Bai et al. ${ }^{(1)}$ inferred that, for an acupuncture action to be effective, it is essential to deep insertion of the needle points for specific brain areas to be stimulated and to prolong the effects of acupuncture, even after removal of needles. Therefore, it is demonstrated that the effectiveness of acupuncture depends on the proper choice of acupoints and the depth of insertion. It must be emphasized that many of these studies have used some of acupoints used in the treatment of group I, as PC6, CV12, ST36, ST44.

Based on the acupuncture points specificity on the generation of neuronal responses a major study was conducted in China which included 712 patients with $\mathrm{FD}^{(10)}$. In this study, the patients received acupuncture treatment during four consecutive weeks and were evaluated at the end of therapy, and three months after, methodology similar to our study. The authors demonstrated that the group which received acupuncture in specific points obtained a significant gastrointestinal symptoms reduction when compared to the group using sham points. In a prospective, randomized study, conducted in Brazil, Silva et al. ${ }^{(18)}$ evaluated the efficacy of acupuncture in the treatment of dyspeptic pregnant women and observed significant improvement of these symptoms in the group treated with specific acupoints for this disorder.

It is known that gastrointestinal functional disorders, among them FD, has a negative impact on the quality of life indices and commonly associated with psychiatric disorders mainly anxiety, depression, somatoform disorder and a history of sexual or physical abuse ${ }^{(19)}$. The relationship between psychological factors and functional dyspepsia pathogenesis is not yet fully established, but it is likely that these variables act in the modulation of visceral sensitivity, a variable clearly involved in FD pathogenesis. In this study, to examine the presence of anxiety and depression and measuring the quality of life the HADS and the SF-36 questionnaire were used, respectively. In this study, it was observed that the group subjected to acupuncture in specific points showed significant 
improvement of psychic symptoms at the end of treatment and after three months of follow-up, as well as the quality of life. Acupuncture has been widely used for the treatment of emotional disorders, such as anxiety and depression, but the effectiveness of this technique under such conditions is not yet fully established ${ }^{(12,15)}$.

Several studies point to the endogenous opioids and neurotransmitters as acupuncture therapeutic action's main mediators. Peripheral nociceptors stimulation produced by the insertion of needles activates nerve fibers that generate impulses that ascend through the spino-thalamic tract to the midbrain, pons and medulla. This process results in neurotransmitters production like serotonin, norepinephrine and opioids. Most likely serotonin, a neurotransmitter interferes in the endorphins and ACTH production, would be responsible for the increased cortisol via the pituitary gland, and its direct action on the cerebral cortex by promoting effects against stress and anxiety ${ }^{(16)}$. Therefore, it is possible to infer that the psychiatric symptoms and quality of life improvement is secondary to the release of neurotransmitters and opioids promoted by acupuncture. The improvement of emotional disorders probably has a positive impact on the quality of life.

Considering the above, it is evident that the association of specific acupuncture with conventional drug therapy in FD patients provided more effective results in all measured variables (gastrointestinal symptoms, anxiety, depression and quality of life) even after 3 months of follow-up. Acupuncture as a complementary treatment can be an important strategy in the search for a more integrated individual treatment, especially in chronic and recurrent disorders such as FD. New studies comparing acupuncture effects as a single therapy and with a greater number of patients must be performed to definitively establish the role of acupuncture in the treatment of functional dyspepsia.

\section{ACKNOWLEDGMENTS}

We express our gratitude to FAPEMIG, Research Foundation of Minas Gerais, which partially funded this research.

Lima FAR, Ferreira LEVVC, Pace FHL. Eficácia da acupuntura como terapia complementar em pacientes com dispepsia funcional. Arq Gastroenterol. 2013,50(3):202-7.

RESUMO - Contexto - A dispepsia funcional representa uma frequente desordem gástrica da prática clínica. Segundo os critérios de Roma III, pode ser subdividida em dois tipos: do tipo dor epigástrica e tipo desconforto pós prandial, de acordo com o sintoma predominante. Embora de fisiopatologia incerta, a dispepsia funcional parece estar relacionada a múltiplos mecanismos, entre eles: a hipersensibilidade visceral, alterações da motilidade gastroduodenal e acomodação gástrica e participação de fatores psíquicos. Objetivos - Avaliar a eficácia da acupuntura como forma complementar ao tratamento medicamentoso em pacientes com dispepsia funcional. Método - Ensaio clínico randomizado, com portadores de dispepsia funcional, segundo os critérios de Roma III. Dois grupos foram formados: Grupo I (terapia medicamentosa e acupuntura específica) e; II (terapia medicamentosa e acupuntura não específica). Foram avaliados o índice de sintomas gastrointestinais, a presença de transtornos psíquicos e a qualidade de vida no início, no fim e 3 meses após o tratamento. Resultados - Após 4 semanas de tratamento houve melhora dos sintomas gastrointestinais no Grupo I ( $55 \pm 12$ vs $29 \pm 8,8 ; P=0,001)$ e no Grupo II ( $50 \pm 10$ vs $46 \pm 10,5 ; P=0,001)$. Na comparação intergrupos, os sintomas gastrintestinais $(29 \pm 8,8$ vs $46 \pm 10,5 ; P<0,001)$ e os sintomas de ansiedade $(0 \%$ vs $41,7 \% ; P=0,003)$ foram significativamente menores no Grupo I e a qualidade de vida $(102,4 \pm 5,1$ vs $96,4 \pm 6,1 ; P=0,021)$ também foi significativamente melhor neste grupo. Três meses após o tratamento, os sintomas gastrointestinais permaneceram melhores no Grupo I, quando comparados aos valores pré-tratamento ( $38 \pm 11,3$ vs $55 \pm 12 ; P=0,001)$. Conclusão - Em portadores de dispepsia funcional, o tratamento complementar com acupuntura é superior ao tratamento convencional.

DESCRITORES - Terapia por acupuntura. Terapia complementar. Dispepsia. 


\section{REFERENCES}

1. Bai L, Tian J, Zhong C, Xue T, You Y, Liu Z, Chen P, Gong Q, Ai L, Qin W, Dai J, Liu Y. Acupuncture modulates temporal neural responses in wide brain networks: evidence from fMRI study. Mol Pain. 2010;6:73.

2. Camilleri M, Tack JF. Current medical treatments of dyspepsia and irritable bowel syndrome. Gastroenterol Clin North Am. 2010;39:481-93.

3. Ceniceros S, Brown GR. Acupuncture: a review of its history, theories, and indications. South Med J. 1998;91:1121-5.

4. Ciconelli RM. Validação do questionário de qualidade de vida "medical outcomes study 36" - item short - form health survey (SF-36). [dissertation]. São Paulo: Escola Paulista de Medicina da Universidade Federal de São Paulo; 1997.

5. Focks C. Atlas de acupuntura, com sequencia de fotos, ilustrações, textos didáticos e ilustrações clínicas. São Paulo: Manole; 2005.

6. Graham DY, Rugge M. Clinical practice: diagnosis and evaluation of dyspepsia. J Clin Gastroenterol. 2010;44:167-72.

7. Hui KK, Liu J, Makris N, Gollub RL, Chen AJ, Moore CI, Kennedy DN, Rosen BR, Kwong KK. Acupuncture modulates the limbic system and subcortical gray structures of the human brain: evidence from fMRI studies in normal subjects. Hum Brain Mapp. 2000;9:13-25.

8. Hui KK, Nixon EE, Vangel MG, Liu J, Marina O, Napadow V, Hodge SM, Rosen BR, Makris N, Kennedy DN. Characterization of the "deqi" response in acupuncture. BMC Complement Altern Med. 2007;7:33.

9. Lin X, Liang J, Ren J, Mu F, Zhang M, Chen JD. Electrical stimulation of acupuncture points enhances gastric myoelectrical activity in humans. Am J Gastroenterol. 1997;92:1527-30.

10. Ma TT, Yu SY, Li Y, Liang FR, Tian XP, Zheng H, Yan J, Sun GJ, Chang XR, Zhao L, Wu X, Zeng F. Randomised clinical trial: an assessment of acupuncture on specific meridian or specific acupoint vs. sham acupuncture for treating functional dyspepsia. Aliment Pharmacol Ther. 2012;35:552-61.

11. MacPherson H, White A, Cummings M, Jobst KA, Niemtzow RC. Standards for reporting interventions in controlled trials of acupuncture: the STRICTA recommendations. Clin Acupunct Oriental Med. 2002;3:6-9.

12. Manni L, Albanesi M, Guaragna M, Barbaro Paparo S, Aloe L. Neurotrophins and acupuncture. Auton Neurosci. 2010;157:9-17.

13. Marcolino JA, Mathias LA, Piccinini Filho L, Guaratini AA, Suzuki FM, Alli LA Hospital Anxiety and Depression Scale: a study on the validation of the criteria and reliability on preoperative patients. Rev Bras Anestesiol. 2007;57:52-62.
14. Noguchi E. Mechanism of reflex regulation of the gastroduodenal function by acupuncture. Evid Based Complement Alternat Med. 2008;5:251-6.

15. Pilkington K, Kirkwood G, Rampes H, Cummings M, Richardson J. Acupuncture for anxiety and anxiety disorders--a systematic literature review. Acupunct Med. 2007;25:1-10.

16. Pilkington K. Anxiety, depression and acupuncture: A review of the clinical research. Auton Neurosci. 2010;157:91-5.

17. Shiotani A, Tatewaki M, Hoshino E, Takahashi T. Effects of electroacupuncture on gastric myoelectrical activity in healthy humans. Neurogastroenterol Motil. 2004;16:293-8.

18. Silva JB, Nakamura MU, Cordeiro JA, Kulay L Jr, Saidah R. Acupuncture for dyspepsia in pregnancy: a prospective, randomised, controlled study. Acupunct Med. 2009;27:50-3.

19. Silva RA, Pinheiro RT, da Silva RA, Horta BL, Moraes I, Faria AD. Functional dyspepsia and depression as an associated factor. Arq Gastroenterol. 2006;43:293-8.

20. Soo S, Forman D, Delaney BC, Moayyedi P. A systematic review of psychological therapies for nonulcer dyspepsia. Am J Gastroenterol. 2004;99:1817-22.

21. Stolte M, Meining A. The updated Sydney system: classification and grading of gastritis as the basis of diagnosis and treatment. Can J Gastroenterol. 2001;15:591-8

22. Svedlund J, Sjödin I, Dotevall G. GSRS - a clinical rating scale for gastrointestinal symptoms in patients with irritable bowel syndrome and peptic ulcer disease. Dig Dis Sci. 1988;33:129-34.

23. Thumshirn M, Camilleri M, Saslow SB, Williams DE, Burton DD, Hanson RB Gastric accommodation in non-ulcer dyspepsia and the roles of Helicobacter pylori infection and vagal function. Gut. 1999;44:55-64.

24. White AR, Filshie J, Cummings TM. Clinical trials of acupuncture: consensus recommendations for optimal treatment, sham controls and blinding. Complement Ther Med. 2001;9:237-45.

25. Yamamura Y. A arte de inserir. 2a ed. São Paulo: Roca; 2001.

26. Yin J, Chen JD. Gastrointestinal motility disorders and acupuncture. Auton Neurosci. 2010;157:31-7.

27. Zeng F, Qin W, Ma T, Sun J, Tang Y, Yuan K, Li Y, Liu J, Liu X, Song W, Lan L, Liu M, Yu S, Gao X, Tian J, Liang F. Influence of acupuncture treatment on cerebral activity in functional dyspepsia patients and its relationship with efficacy. Am J Gastroenterol. 2012;107:1236-47.

28. Zhao ZQ. Neural mechanism underlying acupuncture analgesia. Prog Neurobiol. 2008;85:355-75. 